\title{
Carrion subsidies provided by fishermen increase predation of beach-nesting bird nests by facultative scavengers
}

\author{
J. D. Rees ${ }^{1,2}$, J. K. Webb³, M. S. Crowther ${ }^{1}$ \& M. Letnic ${ }^{2}$ \\ 1 School of Biological Sciences, University of Sydney, Sydney, NSW, Australia \\ 2 Centre for Ecosystem Science, School of Biological Sciences, University of New South Wales, Sydney, NSW, Australia \\ 3 School of Environmental Sciences, University of Technology Sydney, Sydney, NSW, Australia
}

\author{
Keywords \\ anthropogenic resource; artificial nest; \\ carrion; fisheries; nest predation; shorebird; \\ scavenger; spill-over predation.

\section{Correspondence \\ James D. Rees, School of Biological \\ Sciences, The University of New South \\ Wales, Sydney, NSW 2052, Australia. \\ Tel: +61 413228213 \\ Email: james.rees@live.com.au \\ Editor: Trevor Branch \\ Associate Editor: Vincenzo Penteriani}

Received 30 December 2013; accepted 9 April 2014

doi:10.1111/acv.12133

\begin{abstract}
Many predators are also scavengers that feed on carrion and human refuse. Therefore, the availability of carrion can elevate the abundance or activity of facultative scavengers, amplifying predation pressure on prey. On Australian beaches, fishermen often discard fish carcasses that could attract facultative scavengers, both native, such as Australian ravens Corvus coronoides, and invasive, such as European red foxes Vulpes vulpes, and result in elevated rates of predation on wildlife. We tested whether the presence of fish carcasses increased the risk of depredation for nearby nests of beach-nesting birds by deploying artificial nests in 12 subsidized and 12 control patches, spaced $1 \mathrm{~km}$ apart, on a beach. We placed a fish carcass in each subsidized patch, but not at control patches. In each patch, we placed two artificial nests, which resembled redcapped plover Charadrius ruficapillus nests, $80 \mathrm{~m}$ apart and $40 \mathrm{~m}$ from carcasses at subsidized patches. Nest predators were identified from tracks and predator activity near subsidized and control nests was measured by counting tracks crossing a straight transect $(220 \mathrm{~m})$. The activity of a native predator, the Australian raven, was 17 times higher near $(<80 \mathrm{~m})$ nests with fish carcasses than nests without carcasses. After 72 h, $96 \%$ of nests near carcasses were depredated compared with $30 \%$ of nests without carcasses. Ravens were identified as the culprit for $80 \%$ of depredated nests. Although other predators were present in the study area, they did not depredate artificial nests in this experiment. Previous studies have highlighted the effects of permanent and/or large-scale food resources on scavenger abundance and impact. A key management implication of our study is that even small, sparsely distributed, temporally irregular food subsidies, provided by humans, can elevate the activity and predatory impacts of facultative scavengers.
\end{abstract}

\section{Introduction}

If alternate food sources are available, prey-switching generalist predators can suppress the populations of their secondary prey species to critically low levels and even extinction (Sinclair et al., 1998). Many predators are also scavengers that feed on, but are not dependent on, carrion and human refuse. Thus the availability of carrion could elevate predator abundance or activity, amplifying the predatory impacts of these facultative scavengers on their prey (Sinclair et al., 1998; Kristan \& Boarman, 2003).

In many ecosystems, carrion is a temporally and spatially unpredictable resource (Towne, 2000; Roth, 2003;
Cortés-Avizanda et al., 2012). However, the expansion of human society has increased the availability of carrion in many areas (e.g. Votier et al., 2004). For example, at refuse tips, abattoirs, fish-cleaning stations, boat-ramps and on roads where road kill is a frequent occurrence, carrion is regularly available (Angelstam, 1986; Andren, 1992; Haskell, Knupp \& Schneider, 2001; Boarman, 2003; Newton, 2004). In areas such as these, carrion subsidies allow populations of generalist predators to maintain high densities independent of the abundance of prey, leading to hyper-predation [sensu (Sinclair et al., 1998)] of prey (Kristan \& Boarman, 2003; Votier et al., 2004).

Several studies have documented the effects of reliable, long-lived resource subsidies (e.g. refuse tips, urban 
development, carcass dumps) on facultative scavengers and their prey (e.g. Boarman, 2003; Kristan \& Boarman, 2003; Cortés-Avizanda et al., 2009b). However, the effects of small, ephemeral carrion subsidies on facultative scavenger-prey interactions are less well-understood. Since many human activities result in the provision of small, sparsely distributed quantities of carrion, such as offal piles from kangaroo harvesting and fishing, the implications for wildlife could be widespread (Votier et al., 2004; Wilson \& Read, 2004). Understanding the implications of carrion-producing activities is important, so that practices can be refined to minimize impacts on wildlife.

In Australia, populations of beach-nesting birds (BNBs) are declining and nest predation is a contributing factor (Mahon, 2009). Introduced European red foxes Vulpes vulpes (hereafter 'foxes') and native ravens Corvus sp. (hereafter 'ravens') and silver gulls Chroicocephalus noevaehollandiae (hereafter 'gulls') are thought to be the major predators responsible for nest losses (Maguire, Stojanovic \& Weston, 2009; Mahon, 2009). Foxes, ravens and gulls all scavenge carrion, occur in high densities in coastal areas and frequently forage on beaches (Meek \& Saunders, 2000; Higgins, Peter \& Cowling, 2006; Allen, Goullet \& Palmer, 2012). In eastern Australia, fishing is a popular activity. In a survey of coastal areas surrounding our study area, an average of 4.8 and 2.5 fishermen $/ 2 \mathrm{~km}$ of coastline were counted at peak times during school holidays and term time respectively (Kingsford, Underwood \& Kennelly, 1991). Fishermen often discard fish carcasses on beaches, sometimes close $(<200 \mathrm{~m})$ to BNB nests (J.D. Rees, pers. obs.). This practice could potentially attract facultative scavengers, with deleterious consequences for BNBs (Marzluff \& Neatherlin, 2006).

Many important BNB breeding areas are located on or adjacent to beaches, which are often far from developed areas but are frequently (>one fisherman, once/week) visited by small numbers of recreational fishermen who gain access to the beaches using four-wheel-drive vehicles. At these breeding areas, carrion waste from fishermen could potentially increase the activity of facultative scavengers (Neatherlin \& Marzluff, 2004; Marzluff \& Neatherlin, 2006), thereby increasing depredation of BNB nests (Wilcove, 1985). Previous studies have linked discard rates from large, commercial fisheries to prey-switching behavior in avian facultative scavengers and depressed populations of sympatric seabird prey (Votier et al., 2004). However, few studies have documented a direct causal connection between small carrion subsidies and local increases in nest depredation. Despite the potential importance of subsidized facultative scavengers in Australian ecosystems, where obligate scavengers are absent, little has been published on scavenging processes in this region (Brown, Field \& Letnic, 2006; O'Brien et al., 2010). Here we investigate if the presence of a relatively small, temporary resource subsidy, in the form of a fish carcass, increases: (1) the activity of facultative scavengers and (2) the risk of nest depredation for BNBs.

\section{Materials and methods}

To test whether fish scraps discarded by beach fishermen result in an increase in shorebird nest depredation, we conducted an artificial nest experiment in February 2011 on Stockton Beach, a 32-km-long ocean beach surrounded by native vegetation near Newcastle, NSW. We established 24 patches at $1-\mathrm{km}$ intervals, alternating between food subsidized $(n=12)$ and control patches $(n=12)$. Each patch contained two artificial nests spaced $80 \mathrm{~m}$ apart.

We constructed artificial nests to mimic those of the redcapped plover (RCP) Charadrius ruficapillus (Fig. 1a and b) and deployed them in February, which is during this species' breeding season. We placed nests in the dunes, often close to ephemeral wetlands in likely nest locations (Marchant \& Higgins, 1993), including on shell middens or among scattered charcoal or small stones and among dune vegetation. These nest sites are typical of those selected by RCPs and we observed RCP pairs breeding in these locations.

On the coastal beaches of Australia, territorial pairs of RCPs usually nest separately (Marchant \& Higgins, 1993). In the study area, we did not observe natural nests closer
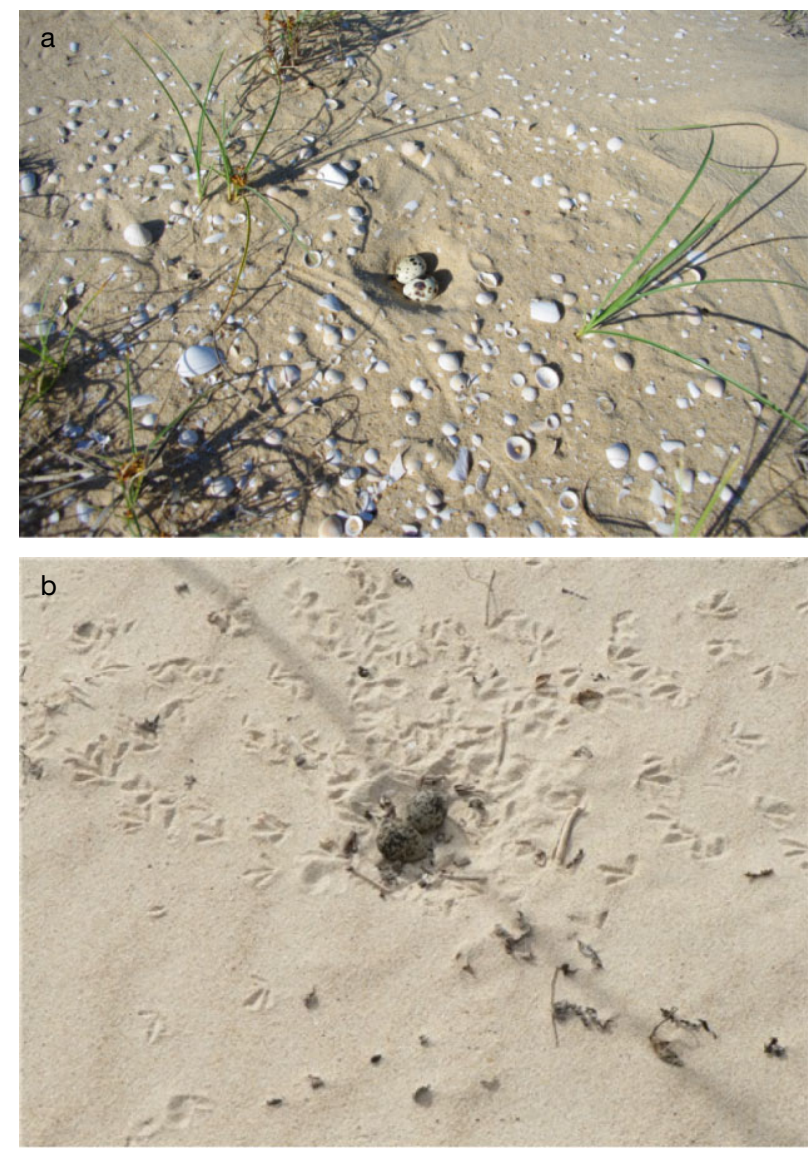

Figure 1 Photographs of (a) an artificial nest deployed in this study and (b) a red-capped plover (RCP) nest. Artificial nests were similar to RCP nests in situation and appearance (photograph of RCP nest by Colin Ashford) 
than $300 \mathrm{~m}$ apart. However, we did not thoroughly search for natural nests. Where loose aggregations of nesting RCPs have been observed, nesting densities of 70-100 $\mathrm{m}$ between nests is normal, with nests rarely closer than $28 \mathrm{~m}$ apart (Marchant \& Higgins, 1993). Therefore the density of our artificial nests (80-m separation within each patch and $1-\mathrm{km}$ between patches) was consistent with natural RCP nesting densities in coastal south-east Australia (Marchant \& Higgins, 1993).

At each nest site, we made a shallow scrape [10-cm diameter, 1.3-cm deep (Marchant \& Higgins, 1993)] into which we placed two eggs. RCPs almost invariably produce two eggs per clutch (Marchant \& Higgins, 1993). We used eggs of the Japanese quail Coturnix japonica because they are similar in size, shape and coloration to RCP eggs [size of $34 \times 27 \mathrm{~mm}$ (Kumari et al., 2008) vs. $31 \times 23 \mathrm{~mm}$ respectively (Marchant \& Higgins, 1993)].

In artificial nest experiments, the lack of parent birds may bias the likelihood of predation towards particular predators, and therefore artificial nests may be depredated by different predators and at different rates to natural nests (Willebrand \& Marcstrom, 1988; Santisteban, Sieving \& Avery, 2002). A common concern is that artificial nests may lack parent bird odour (Ortega et al., 1998). RCPs do not use feathers in the construction of nests and do not defecate at nest sites, minimizing the sources of olfactory cues that could attract predators (Marchant \& Higgins, 1993). Despite these precautions, subtle odour likely exists at RCP nests, detectable to mammalian predators but not humans. We placed quail eggs in the field within $6 \mathrm{~h}$ of obtaining them from quail nests within an aviary, to ensure our nests retained parent bird odour, and the experiment only ran for $72 \mathrm{~h}$.

At each carrion subsidized patch, we placed a filleted carcass of a large $(\sim 75 \mathrm{~cm} ; 1-2 \mathrm{~kg}$ filleted weight) Atlantic salmon Salmo salar $40 \mathrm{~m}$ from each nest. The Atlantic salmon carcasses are similar in size and appearance to those of eastern Australian salmon Arripis trutta, a common waste discarded by fishermen in the study area. We obtained fresh fish carcasses from a fish monger and distributed them in the field within $12 \mathrm{~h}$. We placed carcasses and nests on beaches between 08:00 $\mathrm{h}$ and 12:00 h. To prevent ravens observing nest and carcass placement, we used binoculars (Nikon Monarch $10 \times 42$ ) to scan the surroundings of each nest site for ravens. If ravens were detected, we did not place the nest or carcass and moved on to the next patch. No carcasses were placed in control patches. We did not use markers to indicate nest locations to avoid associative learning by predators.

We checked nests $72 \mathrm{~h}$ after placement and because most treatment nests had been depredated, we terminated the experiment at this point. A nest was considered depredated if one or both eggs were missing or damaged. We determined predator identity from tracks and observations of nest damage. Ravens typically removed both eggs, although sometimes tiny shell fragments were observed beside raven tracks. Ravens can swallow quail eggs whole (J.D. Rees, pers. obs.). The tracks of ravens and gulls are easily distin- guishable as ravens and gulls feet are distinct. Ravens feet are non-webbed and have a long, clawed hind toe, while gulls feet are webbed and have a small hind toe. We only observed the raven species Australian raven Corvus coronoides in the study area. Fox predation of nests is characterized by partial cracking of the egg shells and footprints are usually visible in the sand (Maguire et al., 2009).

When we checked nests, $72 \mathrm{~h}$ after we placed them, we also recorded predator activity at each site by walking a straight transect, following a random compass bearing starting at the fish carcass for subsidized nests or at a point $40 \mathrm{~m}$ in a random direction from the nest for control nests. We recorded raven and fox tracks crossing transects between each $20-\mathrm{m}$ interval, over a distance of $220 \mathrm{~m}$ from the start point. We also used tracks to determine whether foxes or ravens had scavenged on carcasses. At two control sites, tracks from four-wheel-drive vehicle activity prevented us from obtaining reliable track counts on track-transects.

We used repeated measures analysis of variance (ANOVA) to investigate the effects of fish carcasses (presence/absence) and distance from fish carcasses (0-20 m, 20-40 m, 40-60 m, 60-80 m, 80-100 m, 100-120 m, 120$140 \mathrm{~m}, 140-160 \mathrm{~m}, 160-180 \mathrm{~m}, 180-200 \mathrm{~m}, 200-220 \mathrm{~m})$ on raven activity (number of raven tracks crossing the transect/ $20 \mathrm{~m}$ ). Carcass was the 'between' factor and distance was the 'within' factor in repeated measures ANOVA. Mauchly's sphericity test indicated a lack of sphericity in the data and hence probability values were adjusted using the Huynh-Feldt epsilon. Single degree of freedom contrasts were used to determine if there were differences between treatment means for the effect of distance. To determine if the likelihood of a nest being depredated was affected by the presence of fish carcasses, we analysed the data as a generalized linear mixed model with a binomial distribution, using the 'glmmML' package in the statistical program $\mathrm{R}$ (version 2.12.1; www.r-project.org). We gave nest survival (depredated or survived) as the response variable, treatment (carcass or control) as the predictor variable and patch as the random variable, to account for the nested design of the experiment.

\section{Results}

Raven activity was higher at subsidized sites (within $80 \mathrm{~m}$ of carcasses) than at control sites (carcass, $F_{1,20}=18.16$, $P<0.001)$ and decreased with distance from carcass at sites where fish carcasses were placed (Fig. 2; distance $F_{10200}=19.45, P<0.001$; carcass $\times$ distance, $F_{10200}=15.70$, $P<0.001)$. The increase in raven activity at subsidized sites was focused within $80 \mathrm{~m}$ of fish carcasses (Fig. 2) and was significantly greater at sites with fish carcasses at $\quad 0-20 \mathrm{~m} \quad \bar{x}$ (carcass $)=13.67 \pm 2.6, \quad \bar{x}($ control $)=0$, $\left.t_{1,20}=-4.296, P<0.001\right], 20-40 \mathrm{~m} \quad \bar{x}$ (carcass) $=2.67 \pm 0.71$, $\bar{x}($ control $\left.)=0.11 \pm 0.11, \quad t_{1,20}=-2.512, P=0.02\right], 40-60 \mathrm{~m}$ $\bar{x}($ carcass $)=2 \pm 0.51, \quad \bar{x}($ control $)=0.22 \pm 0.15, \quad t_{1,20}=$ $-3.151, P=0.005]$ and $60-80 \mathrm{~m} \bar{x}$ (carcass) $=1.75 \pm 0.66$, $\bar{x}($ control $\left.)=0, t_{1,20}=-2.132, P=0.05\right]$ from carcasses. Fox 


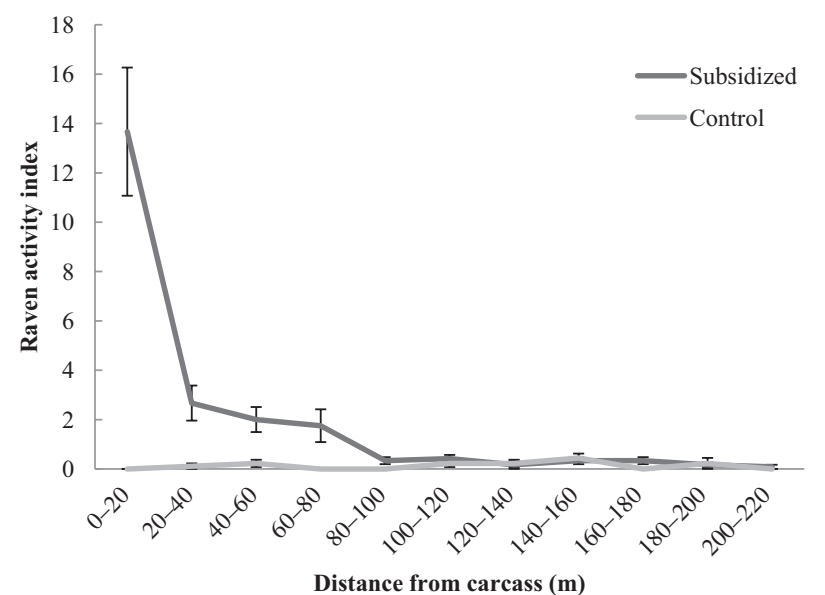

Figure 2 Raven activity (number of tracks crossing/20 m) along transects at sites with and without experimentally placed fish carcasses on Stockton Beach, NSW. Graph shows mean values \pm 1 SE.

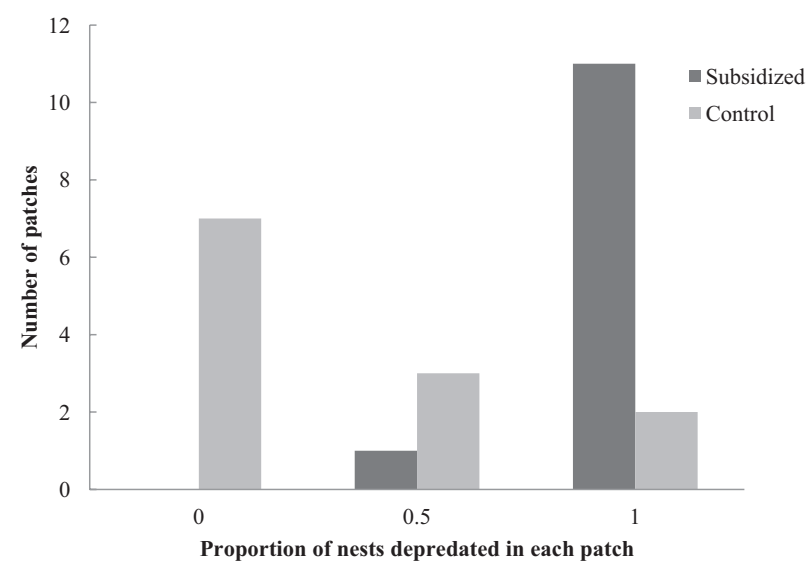

Figure 3 Proportion of sites with and without experimentally placed fish carcasses in which both nests, one nest or no nests were depredated after $72 \mathrm{~h}$. Twenty-four study sites were spaced $1 \mathrm{~km}$ apart and each site contained two artificial nests spaced $80 \mathrm{~m}$ apart. A filleted carcass of an Atlantic salmon was placed $40 \mathrm{~m}$ from the nests at fish carcass sites, but not at control sites.

tracks were found near $(0-20 \mathrm{~m})$ fish carcasses at five subsidized sites but were absent at control sites.

The presence of fish carcasses resulted in increased nest depredation $\left(\beta_{1}=6.17, \mathrm{sE}=1.08, P=0.006\right.$, Fig. 3$)$. After $72 \mathrm{~h}, 96 \%$ of nests near carcasses were depredated, compared with $30 \%$ of control nests. Ravens were identified as predators at $80 \%$ of depredated nests. All depredated nests without identifiable tracks had both eggs removed, suggesting that they had also been consumed by ravens. Neither fox nor gull tracks were observed at any of the depredated nests.

\section{Discussion}

We found that fish waste on beaches provided a resource subsidy for Australian ravens, which increased the activity and predatory impact of this facultative scavenger. In our experiment, ravens rapidly ( $<72 \mathrm{~h}$ ) located and fed on small (1-2 kg), widely dispersed fish carcasses and depredated nests in surrounding areas $(<40 \mathrm{~m})$. We did not test how distance from carcasses affected the likelihood of nest depredation, but in our experiment ravens readily located and depredated nests placed $40 \mathrm{~m}$ from carcasses. Raven activity (as measured by track counts) was highest within $80 \mathrm{~m}$ of fish carcasses, suggesting that nests within this distance of fish carcasses are likely at heightened risk of predation by ravens.

After 72 h, 30\% of control nests had been depredated. This depredation rate is consistent with the results of a pilot study we completed at Stockton Beach, in which 23 and $36 \%$ of 22 artificial plover nests were depredated after $48 \mathrm{~h}$ and $96 \mathrm{~h}$ respectively. At the cessation of that pilot study, at 18 days, $66 \%$ of nests had been depredated. Marchant \& Higgins (1993) reported a similar nest failure rate of $75 \%$ for RCPs. In hooded plovers, another small, Australian beachnesting plover, $60.2 \%$ of nests fail (Dowling \& Weston, 1999). Our pilot study was only $3 / 5$ of the duration of an actual RCP incubation period [30 days (Marchant \& Higgins, 1993)] and had depredation rates remained constant, no nests would have survived to hatching. However, most depredation occurred within the first 10 days and decreased markedly thereafter. This increased probability of survival with each day a nest remains undiscovered has been reported previously (Gunnarsson and Elmberg, 2008), and apparently reflects nests in less favorable positions being robbed early rather than temporal variation in predator abundance.

Our findings support previous studies that have linked human-derived food subsidies to increases in predation by crows and ravens on their prey (Marzluff et al., 2001; Boarman, 2003). Most of these studies have highlighted the effects of permanent and/or large-scale food resources (refuse tips, camp grounds and carcass dumps) on crow and raven abundance (Neatherlin \& Marzluff, 2004; Marzluff \& Neatherlin, 2006; Cortés-Avizanda et al., 2009a). By contrast, we found that even small, sparsely distributed, ephemeral resource subsidies can elevate the activity and predatory impact of ravens.

BNBs are particularly vulnerable to predation resulting from localized increases in raven activity associated with carrion, because their nesting habitat is spatially restricted and because many species depend on the eggs and incubating parent remaining undetected by predators to avoid nest depredation (Marchant \& Higgins, 1993). Our results demonstrated that the likelihood of a nest being discovered by a raven increases with raven activity. Although carcasses were focal points for raven activity, ravens also increased their activity within the vicinity of carcasses and were observed foraging, caching food from the carcass and perching on vegetation in areas surrounding carcasses. While engaged in these exploratory behaviors, ravens likely incidentally discovered and depredated nests near carcasses. Where regular fishing results in the repeated provision of carrion at multiple locations, large areas and large numbers of nests could 
be impacted by scavenging ravens, threatening the viability of BNB breeding sites, which are limited in number and size.

Our findings suggest that ravens are likely a more important predator of BNB nests than indicated by nest survival records, which are maintained by managers of BNB breeding areas. Such records usually contain large numbers of unknown nest losses due to the difficulty identifying nest predators (Harris \& Dunn, 2009). For example, at a little tern Sternula albifrons nesting colony at Lake Wollumboola in NSW, managers could not determine the predators responsible for tern nest losses because predator tracks could not be detected in the shell-grit substrate (Harris \& Dunn, 2009). Only when a wash-over removed the shellgrit, leaving a sand substrate, were ravens identified as the main predator of nests. At this colony, Australian ravens depredated all tern nests, within days of laying, during the 2009/2010 breeding season (Harris \& Dunn, 2009). The site was abandoned by breeding adult terns in the subsequent season.

While it is possible the lack of parent birds in our artificial nest experiment could lead to our overrepresentation of ravens as RCP nest predators (see Methods), we believe our results likely approximate the natural situation due to our experimental design. Our artificial nests retained a mild parent bird odour (see Methods), a cue more commonly used by mammalian, than by avian, predators to locate nests (Clark \& Wobeser, 1997). Despite the nest odour, mammalian predators did not discover nests in this experiment. This result is consistent with observations of foxes and dingoes passing unawares, directly over, or within a few meters of, active plover nests on beaches in Victoria (Birdlife Australia Beach Nesting Birds Project; http:// www.birdlife.org.au/projects/beach-nesting-birds/research) and within the study area (J.D. Rees, pers. obs.).

Another concern associated with artificial nest experiments is that at natural nests parent birds conceal eggs while incubating, so artificial nests are likely more conspicuous from above (Angelstam, 1986). However, when incubating RCPs are disturbed by ravens or crows flying overhead, they slip quietly off the nest, run rapidly away for $c .50 \mathrm{~m}$ and often stand motionless until the danger has passed (Marchant \& Higgins, 1993). Therefore, when a natural nest is approached by ravens, it is not usually concealed by the parent birds, which rely primarily on the cryptic coloration of the eggs to prevent ravens from discovering the nest.

While there is evidence from other studies that foxes can be important predators of shorebird nests, our study and other studies have identified ravens as a major nest predator (Harris \& Dunn, 2009; Maguire et al., 2009). Although some BNB management programs do conduct control of native avian predators, many focus on controlling invasive predators, such as foxes. This prioritization of invasive predators over native predators, by managers attempting to mitigate predation on wildlife, stems primarily from the perception that predation by native predators is a natural process to which BNBs should be adapted. However, if the predatory impact of ravens is elevated by the availability of humanderived resource subsidies, it cannot be considered a natural process. Indeed, either removing resource subsidies by encouraging fishermen to remove or bury fish wastes and/or conducting control of raven populations will be necessary.

\section{Acknowledgements}

We thank Jodie Dunn and John and Glenyss Rees for their support, and Tony DeMamiel (NSW DECCW) for his support and for facilitating access to the study area.

\section{References}

Allen, L., Goullet, M. \& Palmer, R. (2012). The diet of the dingo (Canis lupus dingo and hybrids) in north-eastern Australia: a supplement to the paper of Brook and Kutt (2011). Rangeland J. 34, 211-217.

Andren, H. (1992). Corvid density and nest predation in relation to forest fragmentation - a landscape perspective. Ecology 73, 794-804.

Angelstam, P. (1986). Predation on ground-nesting birds nests in relation to predator densities and habitat edge. Oikos 47, 365-373.

Boarman, W.I. (2003). Managing a subsidized predator population: reducing common raven predation on desert tortoises. Environ. Manage. 32, 205-217.

Brown, O.J.F., Field, J. \& Letnic, M. (2006). Variation in the taphonomic effect of scavengers in semi-arid Australia linked to rainfall and the El Nino Southern Oscillation. Int. J. Osteoarchaeol. 16, 165-176.

Clark, R.G. \& Wobeser, B.K. (1997). Making sense of scents: effects of odour on survival of simulated duck nests. J. Avian Biol. 28, 31-37.

Cortés-Avizanda, A., Carrete, M., Serrano, D. \& Donázar, J.A. (2009a). Carcasses increase the probability of predation of groundnesting birds: a caveat regarding the conservation value of vulture restaurants. Anim. Conserv. 12, 85-88.

Cortés-Avizanda, A., Selva, N., Carrete, M. \& Donázar, J.A. (2009b). Effects of carrion resources on herbivore spatial distribution are mediated by facultative scavengers. Basic Appl. Ecol. 10, 265-272.

Cortés-Avizanda, A., Jovani, R., Carrete, M. \& Donázar, J.A. (2012). Resource unpredictability promotes species diversity and coexistance in an avian scavenger guild: a field experiment. Ecology 93, 2570-2579.

Dowling, B. \& Weston, M.A. (1999). Managing a breeding population of the hooded plover Thinornis rubricollis in a high-use recreational environment. Bird Conserv. Int. 9, 255-270.

Gunnarsson, G. \& Elmberg, J. (2008). Density-dependent nest predation - an experiment with simulated Mallard nests in contrasting landscapes. Ibis 150, 259-269.

Harris, A. \& Dunn, J. (2009) South Coast Shorebird Recovery Program 2008/09 breeding season. (ed. D.o.E.a.C. Change). 
Haskell, D., Knupp, A.M. \& Schneider, M.C. (2001). Nest predator abundance and urbanization. In Avian ecology and conservation in an urbanizing world: 243-258. Marzluff, J.M., Bowman, R. \& Donnelly, R. (Eds). Norwell: Kluwer Academic.

Higgins, P.J., Peter, J.M. \& Cowling, S.J. (2006). Handbook of Australian, New Zealand and Antarctic Birds, Vol. 7, Boatbill to Starlings. Melbourne: Oxford University Press.

Kingsford, M.J., Underwood, A.J. \& Kennelly, S.J. (1991). Humans as predators on rocky reefs in New South Wales, Australia. Mar. Ecol. Prog. Ser. 72, 1-14.

Kristan, W.B. \& Boarman, W.I. (2003). Spatial pattern of risk of common raven predation on desert tortoises. Ecology 84, 2432-2443.

Kumari, B.P., Gupta, B.R., Prakash, M.G. \& Reddy, A.R. (2008). A study on egg quality traits in Japanese quails (Coturnix coturnix japonica). TNJVAS 4, 227-231.

Maguire, G.S., Stojanovic, D. \& Weston, M.A. (2009). Conditioned taste aversion reduces fox depredation on model eggs on beaches. Wildl. Res. 36, 702-708.

Mahon, P.S. (2009). Targeted control of widespread exotic species for biodiversity conservation: the red fox (Vulpes vulpes) in New South Wales, Australia. Ecol. Manag. Restor. 10, s59-s69.

Marchant, S. \& Higgins, P.J. (1993). Handbook of Australian, New Zealand and Antarctic Birds, Vol. 2, Raptors to Lapwings. Melbourne: Oxford University Press.

Marzluff, J.M. \& Neatherlin, E. (2006). Corvid response to human settlements and campgrounds: causes, consequences, and challenges for conservation. Biol. Conserv. 130, 301-314.

Marzluff, J.M., McGowan, K.J., Donnelly, R.E. \& Knight, R.L. (2001). Causes and consequences of expanding American crow populations. In Avian ecology and conservation in an urbanizing world: 331-363. Marzluff, J.M., Bowman, R. \& Donnelly, R. (Eds). Norwell: Kluwer Academic.

Meek, P.D. \& Saunders, G. (2000). Home range and movement of foxes (Vulpes vulpes) in coastal New South Wales, Australia. Wildl. Res. 27, 663-668.
Neatherlin, E.A. \& Marzluff, J.M. (2004). Responses of American crow populations to campgrounds in remote native forest landscapes. J. Wildl. Manage. 68, 708-718.

Newton, I. (2004). The recent declines of farmland bird populations in Britain: an appraisal of causal factors and conservation actions. Ibis 146, 579-600.

O'Brien, R.C., Larcombe, A., Meyer, J., Forbes, S.L. \& Dadour, I. (2010). The scavenging behaviour of the Australian raven (Corvus coronoides): patterns and influencing factors. Sylvia 46, 133-148.

Ortega, C.P., Ortega, J.C., Rapp, C.A. \& Backensto, S.A. (1998). Validating the use of artificial nests in predation experiments. J. Wildl. Manage. 62, 925-932.

Roth, J.D. (2003). Variability in marine resources affects arctic fox population dynamics. J. Anim. Ecol. 72, 668676.

Santisteban, L., Sieving, K.E. \& Avery, M.L. (2002). Use of sensory cues by fish crows Corvus ossifragus preying on artificial bird nests. J. Avian Biol. 33, 245-252.

Sinclair, A.R.E., Pech, R.P., Dickman, C.R., Hik, D., Mahon, P. \& Newsome, A.E. (1998). Predicting effects of predation on conservation of endangered prey. Conserv. Biol. 12, 564-575.

Towne, E.G. (2000). Prairie vegetation and soil nutrient responses to ungulate carcasses. Oecologia $\mathbf{1 2 2}$, 232-239.

Votier, S.C., Furness, R.W., Bearhop, S., Crane, J.E., Caldow, R.W.G., Catry, P., Ensor, K., Hamer, K.C., Hudson, A.V., Kalmbach, E., Klomp, N.I., Pfeiffer, S., Phillips, R.A., Prieto, I. \& Thompson, D.R. (2004). Changes in fisheries discard rates and seabird communities. Nature 427, 727-730.

Wilcove, D.S. (1985). Nest predation in forest tracts and the decline of migratory songbirds. Ecology 66, 1211-1214.

Willebrand, T. \& Marcstrom, V. (1988). On the danger of using dummy nests to study predation. Auk 105, 378379.

Wilson, D. \& Read, J.L. (2004). Scavengers and detritivores of kangaroo harvest offcuts in arid Australia. Wildl. Res. 31, 51-56. 